\title{
Las actuaciones arqueológicas ante la realización de obras
}

\author{
Manuel Rebollo Puig \\ Catedrático de Derecho Administrativo \\ Universidad de Córdoba ${ }^{1}$
}

\begin{abstract}
SUMARIO: I. PLANTEAMIENTO. II. LAS SOLUCIONES DE LA LEY DEL PATRIMONIO HISTÓRICO ESPAÑOL. 1. Actuaciones arqueológicas previas a obras en zonas BIC. 2. Actuaciones arqueológicas previas a obras en terrenos en los que se presuma la existencia de restos arqueológicos. 3. Actuaciones arqueológicas por hallazgos casuales en la ejecución de obras. 4. Recapitulación. III. LAS SOLUCIONES EN LA LEGISLACIÓN AUTONÓMICA. 1. Actuaciones arqueológicas previas a obras en zonas con una declaración formal de la existencia de restos arqueológicos relevantes. 2. Actuaciones arqueológicas previas a obras en zonas en las que sólo se presume la existencia de restos arqueológicos. 3. Obras en cuya ejecución se producen hallazgos casuales. IV. EN ESPECIAL, LAS PREVISIONES AUTONÓMICAS DE FINANCIACIÓN PÚBLICA DE LAS ACTUACIONES ARQUEOLÓGICAS IMPUESTAS A LOS PROMOTORES DE OBRAS. 1. Ayudas públicas, no indemnizaciones. 2. La completa financiación pública. 3. La exclusión de toda cofinanciación pública. 4. Diversas soluciones intermedias de cofinanciación pública parcial. 5. Precisiones sobre los retrasos, sobre los promotores públicos y sobre los gastos de redacción del proyecto arqueológico. 6. Pronunciamientos judiciales. V. LA AGRAVAGIÓN DE LA SITUAGIÓN EN LOS PLANES DE URBANISMO. VI. VALORACIÓN Y PROPUESTA DE REFORMA.
\end{abstract}

\section{RESUMEN:}

La realización de obras comporta a menudo la necesidad de actuaciones arqueológicas. En este artículo se analiza si tales actuaciones deben ser asumidas y costea-

\footnotetext{
${ }^{1}$ Grupo de Investigación de la Junta de Andalucía SEJ-196. Proyecto de Investigación del Ministerio de Educación y Ciencia DER-2012/35269. El presente trabajo tiene su origen en el elaborado para el Liber amicorum Enrique Gómez-Reino y Carnota bajo el título "La protección del patrimonio arqueológico frente a la realización de obras", trabajo que ahora ha sido actualizado y completado.
} 
das por los promotores de las obras o por la Administración. Se expone la solución que consagró la legislación estatal y las que han establecido las Comunidades Autónomas. Se pone de relieve que éstas se apartan notablemente de lo previsto en la legislación estatal y, a su vez, presentan muchas diferencias entre sí. Las diferencias se agravan por la interferencia de los planes de urbanismo, por la práctica administrativa y por las diversas interpretaciones de los tribunales. Se critica el sistema resultante y se hacen propuestas de modificación para que la legislación estatal garantice un mínimo de igualdad y de racionalidad del sistema.

PALABRAS CLAVE:

Patrimonio arqueológico. Deberes de los promotores. Igualdad. Garantía de la propiedad.

ABSTRACT:

Building works often imply the need for archaeological activities. In this article it is examined if those activities should be undertaken and financed by the promoters of the works or by the Public Administration. The solution which was reached by the state and regional legislation is exposed. It is emphasized that regional legislation deviates significantly from the provisions of state legislation and, at the same time, reveals many differences between them. The differences are aggravated by the interference of the urban development plan, administrative practices and the various interpretations of the courts. The resulting system is criticized and proposals for changes are made, so that state legislation might guarantee a minimum of equality and rationality of the system.

\section{KEYWORDS:}

Archaeological heritage. Duties of promoters. Equality. Guarantee of property.

\section{PLANTEAMIENTO}

Cuando, hasta hace pocos años, había una febril actividad constructiva, se observaba con frecuencia que los terrenos en los que se iba a realizar una obra eran escenario de largas y meticulosas actuaciones arqueológicas que se desarrollaban por numerosos trabajadores. Así, en algunas partes de nuestras ciudades y en aquellas épocas de bonanza la presencia de arqueólogos dejó en poca cosa al Valle de los Reyes. La perplejidad general aumentaba cuando, tras tanto tiempo y esfuerzo, todo terminaba muchas veces sin ningún vestigio conservado y sin que se investigara más sobre los restos que acaso se hubieran encontrado. Sin cuestionar si esas actuaciones arqueológicas cumplieron verdaderamente una función científica y social que las justificase ni criticar tampoco aquel frenesí arqueológico que se produjo al socaire del boom urbanístico -aunque resultase de casi tan difícil digestión como éste-, lo que aquí 
se pretende, ahora que tenemos más perspectiva y sosiego, es ofrecer el panorama del régimen jurídico de estas actuaciones arqueológicas ¿Asume como propias esas intervenciones el promotor de las obras? ¿Qué contenido, alcance y duración pueden tener? ¿Se persigue con ellas sólo evitar que las obras destruyan restos arqueológicos o, por el contrario, pretenden conseguir un estudio científico completo? ¿Quién las costea y, en su caso, con qué límites?

A este respecto nuestro Derecho ha de partir no sólo del art. 46 CE sino del Convenio Europeo para la Protección del Patrimonio Arqueológico (revisado), hecho en La Valeta el 16 de enero de 1992 y ratificado por España el 1 de marzo de 2011. Pero ni la Constitución ni este Convenio condicionan mucho las respuestas legales. En concreto, el Convenio aunque impone desde luego la protección arqueológica frente a las obras, deja abiertas todas las posibilidades de financiación incluso cuando se trate de los "grandes proyectos de infraestructuras" (art. 6).

Hay ya algunos estudios que han analizado agudamente estas cuestiones. De entre ellos, me resulta particularmente esclarecedor el que se contiene en la espléndida tesis doctoral de Rosario Leñero Bohórquez ${ }^{2}$. Tuve la suerte de formar parte del tribunal que la juzgó, lo que me permitió conocer el estado de la cuestión y vislumbrar las respuestas a las interrogantes planteadas y que desde hace tiempo me inquietaban. Pero la lectura de esa tesis, que ante todo recomiendo una vez que por fin sea publicada, también me ha permitido abundar en mi previa impresión de que las soluciones que se vienen dando en España, además de no ser siempre claras y ser fuente de inseguridad jurídica y de desigualdad, no están muchas veces del todo justificadas ni son siempre correctas. Exponerlo es lo que pretendo modestamente en este estudio, pero reconociendo mi deuda con el trabajo de la Dra. Leñero.

Para nuestro propósito cabe distinguir tres tipos de supuestos según los terrenos sobre los que se proyecte realizar las obra: primero, los terrenos que cuentan con una declaración formal de su valor por constar con certeza que albergan restos de relevancia; segundo, aquellos en los que simplemente se sospecha que pudieran exis-

${ }^{2}$ R. LEÑERO BOHÓRQUEZ, La tutela jurídico-administrativa de la funcionalidad del patrimonio arqueológico: dominio público y control administrativo de las actividades arqueológicas, tesis dirigida por los Profs. Núñez Lozano y Barnés Vázquez y defendida en la Universidad de Huelva el 18 de julio de 2011, ante el tribunal presidido por el Prof. López Menudo y formado también por los Profs. Quintana López, Alonso Ibáñez y Carrillo Donaire, además de por mí mismo. Junto a esta tesis que dedica su capítulo IV a las actividades de investigación arqueológica y en el que, además de otros extremos, se analizan los que aquí nos interesan, quien más específicamente se ocupado de ellos y con aportaciones de gran interés es J. BERMÚDEZ SÁNCHEZ: primero en "Mecanismos de protección y financiación en la arqueología urbana", Revista de Administración Pública, no 141 (1996), pp. 95 a 129; y después en El derecho de propiedad: límites derivados de la protección arqueológica, Montecorvo, Madrid, 2003. 
tir restos arqueológicos; y, tercero, aquellos en los que ni siquiera se parte de esos indicios pero en los que, iniciadas ya las obras y como consecuencia de ellas, se produce algún hallazgo ${ }^{3}$. Pero no en todas las leyes la distinción aparece con nitidez y en los mismos términos, además de que se establece una conexión entre los tres regímenes correspondientes, previéndose eventualmente que de un estadio se pase a otro. Aun así, este esquema nos permitirá exponer y comparar las diversas soluciones legislativas.

\section{LAS SOLUGIONES DE LA LEY DEL PATRIMONIO HISTÓ- RICO ESPAÑOL}

\section{Actuaciones arqueológicas previas a obras en zonas BIC}

El punto de partida debe situarse en el art. 22.1 de la Ley 16/1985, de Patrimonio Histórico Español (en adelante LPHE), según el cual "cualquier obra o remoción de terreno que se proyecte realizar en un Sitio Histórico o en una Zona Arqueológica declarados Bien de Interés Cultural deberá ser autorizada por la Administración competente para la protección de dichos bienes, que podrá, antes de otorgar la autorización, ordenar la realización de prospecciones y, en su caso, excavaciones arqueológicas, de acuerdo con lo dispuesto en el Título V de la presente Ley".

Varios son los interrogantes que suscita este precepto, que dista de ser claro. Pero, por lo que aquí interesa, parece que se debe concluir lo siguiente: a) Que se refiere sólo a zonas declaradas previamente BIC lo que supone que ya consta con certeza la existencia de restos arqueológicos de relevancia; b) Que sólo permite acordar la realización de actuaciones arqueológicas con la finalidad de aportar datos para resolver con mejor conocimiento si se debe o no autorizar la realización de las obras, no con la de investigar plenamente esos restos, y que, por tanto, se configura como un acto de instrucción dentro del procedimiento para otorgar o denegar la autorización cultural de las obras; y c) Que las prospecciones o excavaciones se realizarán por la Administración -o persona que designe- y a su costa, de modo que el promotor no sólo no tiene que asumirlas ni sufragarlas ${ }^{4}$ sino que, además, tendrá derecho a ser indemnizado por los daños que eso le irrogue.

${ }^{3}$ Una sistematización similar, aunque no idéntica, sigue J. ALONSO GARCÍA, "Las cargas arqueológicas sobre inmuebles privados: carencia de un régimen sistemático para la imposición de obligaciones y su compensación”, Revista Andaluza de Administración Pública, nº 86 (2013), pp. 151 a 154.

${ }^{4}$ Sería una de las meras "obligaciones de soportar" a las que se refiere J. ALONSO GARCíA, "Las cargas arqueológicas...", cit., pp. 170-171. 
La solución contraria, esto es, la de entender que corresponde al mismo interesado en realizar la obra acometer a su costa las actuaciones arqueológicas, sólo podría aceptarse si estuviese expresa e inequívocamente consagrada en la ley, máxime tratándose de un acto de trámite o instrucción de un procedimiento administrativo. Y no sólo no existe esa consagración legal, sino que de la LPHE se deduce lo contrario. En concreto, se deduce de la remisión que el mismo art. 22.1 LPHE hace al Título V de la Ley, remisión que ha de entenderse hecha más exactamente a su art. 43. Volveremos de inmediato sobre este art. 43. Ahora basta decir que permite a la Administración acordar excavaciones o prospecciones pero que preceptúa que "a los efectos de la correspondiente indemnización regirá lo dispuesto en la legislación vigente sobre expropiación forzosa". Esto conduce derechamente al art. 83 de la Ley de Expropiación Forzosa que se refiere a "la determinación de la indemnización que proceda abonar por la ocupación temporal de inmuebles por causa de excavaciones arqueológicas". O sea que la Administración puede decidir hacer prospecciones o excavaciones pero indemnizando al propietario por la ocupación temporal de su finca; y, claro está, si se va a ocupar temporalmente su finca, es que tales excavaciones las va a hacer la Administración: si se estuviera pensando en que es el mismo propietario el que tiene que hacer y costear las excavaciones, no tendría ningún sentido remitir a la legislación de expropiación forzosa. En la misma dirección: si se le va a indemnizar hasta por la ocupación temporal de sus terrenos, con mayor razón hay que pensar que no se le va a cargar con los costes de las actuaciones arqueológicas. Acaso quepa también recordar que cuando se aprobó la LPHE, en 1985, la LEF no sólo regulaba la expropiación forzosa, incluida la modalidad de las ocupaciones temporales, sino también la responsabilidad patrimonial de la Administración (arts. 121 y ss. LEF), de modo que la referencia genérica a la "correspondiente indemnización" conforme a "lo dispuesto en la vigente legislación de expropiación forzosa" permitía también eventualmente jugar con esa otra institución. En cualquier caso, lo que se colige de este juego combinado de los arts. 22.1 y 43 LPHE y de su remisión a la legislación expropiatoria es que las actuaciones arqueológicas que acuerde realizar la Administración cultural en el procedimiento de autorización de obras no tienen que ser realizadas ni costeadas por el promotor en las zonas declaradas BIC sino por la Administración cultural ${ }^{5}$. Ello sin perjuicio de que mediante tasas pudiera hacerse recaer sobre el solicitante de la autorización los costes de esas actuaciones administrativas arqueológicas necesarias para pronunciarse sobre su solicitud.

${ }^{5}$ Esa es también la conclusión de BERMÚDEZ y de LEÑERO, aunque en ocasiones se muestren dubitativos, no tanto por lo que deducen de la LPHE como por tratar de conciliar con la legislación autonómica que, como veremos, ha invertido la regla. El primero en el Derecho de propiedad...., cit.,sintetiza en p. 72: "El legislador estatal... sólo destaca en principio la financiación pública de las intervenciones arqueológicas... En su caso, sería posible interpretar que del art. 22.1 LPHE podría derivarse ya la obligación de costear por parte del promotor. Esta posibilidad, sin em- 
Ahora bien, si la Administración puede pura y simplemente denegar la autorización para las obras, cabe preguntarse si no podrá someterla a condición. Concretamente, ¿podrá otorgarla a condición de que el promotor asuma a su costa las excavaciones necesarias para una investigación completa de los restos arqueológicos? La respuesta positiva parece lógica y tendría una justificación material razonable: puesto que si el promotor realiza las obras afectará a restos arqueológicos que se perderán y no podrán ser ya estudiados, se le impone como condición que antes haga una investigación completa de esos restos. No sería óbice a esta forma de razonar el que finalmente se permitiera destruir los restos arqueológicos porque el valor de estos muchas veces no es artístico ni estético, sino que deriva exclusivamente de que suministran elementos para un mejor conocimiento de la historia y, por tanto, realizada su documentación e investigación completa, puede no haber inconveniente a su soterramiento o incluso pérdida. Además, desde el punto de vista jurídico, frecuentemente se admiten este género de cláusulas accesorias en los actos administrativos autorizatorios cuando con ellas se evita su denegación o cuando están configurados como discrecionales. En tal caso estaríamos reconociendo a la Administración la potestad de imponer al promotor, no propiamente un deber de afrontar actuaciones arqueológicas, pero sí una condición que genera lo que más exacta y técnicamente sería una carga: si no la cumple -esto es, si no afronta la actuación arqueológica que la Administración juzga conveniente- no estará incurriendo en ninguna ilicitud ni cabrá pasar a la ejecución forzosa, pero no obtendrá el beneficio de realizar las obras. Nótese, además, que por esta vía lo que la Administración cultural podría imponer como condición no sería sólo un estudio de la eventual incidencia arqueológica de las obras sino una investigación total de los restos.

Pese a la lógica de esta alternativa y a sus muchas ventajas, presenta flancos endebles. En realidad, siempre es dudoso que la Administración pueda introducir condiciones en sus actos y buena parte de la doctrina y de la jurisprudencia exigen una

bargo, ... no está claramente expresada en el citado precepto, que también podría interpretarse en sentido contrario, alegando que la remisión que el precepto realiza al título V de la Ley, lo será también a la indemnización estipulada en el art. 43 LPHE...". Vid. también pp. 113-114 y 127. LEÑERO BOHORQUEZ dice que "de la LPHE no se infiere que la orden de la Administración cultural se traduzca en que sea el sujeto interesado en las obras quien deba promover las intervenciones arqueológicas preventivas. Más bien parece que la Ley estatal impone al particular soportarlas, siendo responsabilidad de la Administración cultural su ejecución". Después, bajo el rubro "las ambiguas previsiones de la LPHE sobre el régimen de financiación de las actividades preventivas y de urgencia", afirma que "la LPHE sienta el principio de financiación pública de las intervenciones arqueológicas en espacios donde se presume la existencia de restos arqueológicos... En cambio, resulta dudoso el tratamiento dispensado a las intervenciones arqueológicas preventivas en zonas arqueológicas...". Aun así, concluye que la LPHE mantiene el "principio de financiación pública de las actividades arqueológicas preventivas, cualquiera que sea el escenario en el que se desarrollen". 
expresa previsión legal. Aquí no sólo no existe esa previsión legal sino que parece que la posibilidad de imponer al promotor en la autorización cultural de las obras esa condición de afrontar investigaciones arqueológicas a su costa choca con el tenor literal y con el sentido del art. 22.1 LPHE que, como ya hemos visto, habla de prospecciones o excavaciones "antes de otorgar la autorización", sólo con la finalidad de aportar datos para decidir si debe o no concederse y a costa de la Administración.

\section{Actuaciones arqueológicas previas a obras en terrenos en los que se presuma la existencia de restos arqueológicos}

Las obras en terrenos en los que, sin estar incluidos en una zona BIC, se presuma, aunque sin certeza, la existencia de restos arqueológicos de cualquier valor, no están sometidas por la LPHE a una autorización cultural ni tampoco a la carga de afrontar intervenciones arqueológicas previas ${ }^{6}$. En cambio, contiene la LPHE, en su art. 43, una específica previsión para estos terrenos: "La Administración competente podrá ordenar la ejecución de excavaciones o prospecciones arqueológicas en cualquier terreno público o privado del territorio español, en el que se presuma la existencia de yacimientos o restos arqueológicos, paleontológicos o de componentes geológicos con ellos relacionados. A efectos de la correspondiente indemnización regirá lo dispuesto en la legislación vigente sobre expropiación forzosa"7. Ya explicamos el significado de esta remisión a la legislación expropiatoria y cómo conduce a concluir que las excavaciones o prospecciones acordadas por la Administración, aunque han de ser soportadas por el particular, no deben ser emprendidas ni costeadas por él sino por la Administración que, además, deberá indemnizar los daños que cause. Lo que ahora interesa añadir es que, aunque para servirse de este art. 43 LPHE no es necesario que alguien pretenda realizar obras o esté ya ejecutándolas ni menos aún que se haya producido un hallazgo casual, lo cierto es que, entre otros casos, puede utilizarse ante la realización inminente de obras o ante las ya iniciadas si hay datos que permitan sospechar -por estudios anteriores o incluso por un hallazgo casualque en los terrenos puede haber restos arqueológicos. Es más, resulta especialmente adecuado en ese supuesto de obras inminentes o comenzadas que pudieran destruir hipotéticos restos arqueológicos y, en tal caso, indudablemente, el acuerdo de realizar prospecciones o excavaciones impedirá empezar o continuar las obras. Pero, como decimos, ello sin que el promotor deba hacer otra cosa que soportar las actuaciones arqueológicas: no tendrá que asumirlas ni sufragarlas y será indemnizado por los daños que le causen.

${ }^{6}$ J. BERMÚDEZ SÁNCHEZ, El derecho de propiedad..., cit., p. 89.

${ }^{7}$ Vid. J. L. ÁLVAREZ ÁLVAREZ, Estudios sobre el patrimonio histórico españoly la ley de 25 de junio de 1985, Civitas, Madrid, 1989, p. 781. 


\section{Actuaciones arqueológicas por hallazgos casuales en la ejecución de obras}

Si las obras no se van a desarrollar en una zona declarada BIC ni en aquéllas en las que previamente se hizo uso de la facultad del art. 43 LPHE pero en su ejecución se produce un hallazgo, la LPHE no ofrece una solución específica. Partiendo de que el hallazgo debe comunicarse de inmediato (art. 42.3 in fine) y de que la Administración puede acordar la suspensión de las obras durante treinta días hábiles (art. 37.2, primera parte, LPHE) $)^{8}$, se abren dos posibilidades. La primera y normal es simplemente aplicar el art. 43, esto es, partir ahora de una presunción de restos arqueológicos y, en consecuencia, acordar las actuaciones arqueológicas oportunas a costa de la Administración. La segunda, si hay méritos para ello, iniciar el procedimiento para declarar BIC los terrenos (art. 37.2 in fine), iniciación que ya produce transitoriamente los efectos de la declaración (art. $11 \mathrm{LPHE}$ ) y que, por ende, permitiría aplicar el art. 22.1 de la propia LPHE. O sea, se trata de utilizar los mismos remedios antes vistos pero, en vez de hacerlo previamente, hacerlo a posteriori.

\section{Recapitulación}

Por tanto, en ningún caso la LPHE impone al promotor de obras que asuma como tarea propia la realización de actuaciones arqueológicas. Es siempre una actividad de la Administración que, además, indemnizará por los daños que tales actuaciones comporten. Es así incluso cuando se trate de obras en zonas arqueológicas declaradas BIC. De esta forma queda justificada y paliada la amplísima discrecionalidad que se otorga a la Administración para decidir si se hacen o no esas actuaciones y su alcance. A fin de cuentas, se trata sólo de decidir sobre lo que hará la propia Administración sin que entrañe un deber ni un gasto para los particulares. La financiación es siempre pública ${ }^{9}$.

No puede decirse que no haya en la LPHE un sistema completo y coherente de reacción frente a los peligros que para el patrimonio arqueológico entraña la realización de obras: es un sistema de financiación pública y que sólo consagra controles preventivos para los terrenos en los que hay certeza sobre la existencia de restos re-

${ }^{8}$ Vid. J. ALONSO GARCÍA, “Las cargas arqueológicas...”, cit., pp. 162 a 164.

${ }^{9}$ De hecho, según explica I. RODRÍGUEZ TEMIÑO, Arqueología urbana en España, Ariel, Barcelona, 2004, pp. 52, 92-93, 122, 153, era habitual que las excavaciones las hicieran gratuitamente los servicios arqueológicos de la Administración, sobre todo de los municipios, que, si acaso, cobraban tasas que no cubrían el coste real de la intervención. 
levantes ${ }^{10}$. Cosa distinta es si ese régimen se considera o no el más apropiado. De un lado, es posible que en los terrenos no declarados de interés cultural la Administración no pueda reaccionar a tiempo sino cuando ya se hayan producido algunos daños. De otro lado y sobre todo, requiere unos fondos públicos elevados, casi inasumibles, tanto ante la masiva realización de obras potencialmente perjudiciales, que se dio hasta hace unos años, como ante la penuria actual de las arcas públicas. Además, no siempre parece acertado ni justo que cuando se trata simplemente de evitar que la obra destruya restos arqueológicos el promotor no sólo no afronte ningún gasto sino que haya de ser indemnizado por todos los perjuicios que le causen las intervenciones que se acuerden.

\section{LAS SOLUGIONES EN LA LEGISLACIÓN AUTONÓMICA}

Sobre todo tras la STC 17/1991, con la victoria pírrica del Estado ${ }^{11}$, las Comunidades Autónomas aprobaron sus propias leyes de patrimonio histórico o cultural que se superpusieron a la LPHE y que, de hecho, en gran parte, impiden su aplica-

${ }^{10}$ Se tiende a decir que la LPHE tenía un "vacío" en cuanto a las situaciones intermedias entre el hallazgo casual y la zona en la que hay certeza de la existencia de restos relevantes, esto es, para las obras en terrenos en los que sólo hubiera una presunción de la existencia de restos. Así, I. RODRÍGUEZ TEMIÑO, Arqueología urbana ..., cit., pp. 132-133 y 149. Puede aceptarse, como lo hace este autor, en el sentido de que la LPHE no estableció para esas situaciones un específico régimen preventivo ante la realización de obras. Pero no en el sentido de que hubiera propiamente una laguna jurídica pues para las obras en esos terrenos había un régimen aplicable que era el que se desprendía de su genérico art. 43 y de lo previsto para los hallazgos en obras ya iniciadas. Eso ni siquiera puede considerarse un olvido o un error involuntario sino que más bien parece el fruto de una clara opción legislativa en la que, partiendo de que el control preventivo es el más restrictivo de la libertad, consideró que sólo resultaba proporcionado cuando estuviese comprobada la existencia de restos arqueológicos relevantes y que para cualquier otro caso bastaba la reacción a posteriori. Por ello sólo se consagró la exigencia de autorización cultural de las obras en esos terrenos BIC y, en consecuencia, sólo para ellos se pudo prever las actuaciones arqueológicas previas. Este planteamiento, se comparta o no, está muy lejos de ser disparatado. Cosa diferente es que pueda pensarse que en este ámbito, al igual que en el del medio ambiente, esté justificado que los principios de prevención y de precaución o cautela desplieguen aquí sus efectos. Es esto lo que, mal que bien, late en la legislación autonómica. Pero que la LPHE no lo creyera y plasmara una solución distinta y distante de ésa, no supone ninguna laguna ni ningún error.

${ }^{11}$ Esa STC 17/1991, de 31 de enero, aunque no anuló ningún precepto de la LPHE, lo hizo gracias a una interpretación que, como dijo J. M. ALEGRE ÁVILA, "Los bienes históricos y el Tribunal Constitucional", Revista Española de Derecho Constitucional, no 32 (1991), p. 221, introdujo "graves factores de inseguridad e incoherencia", además de sentar las bases para que, a la postre, pudiera ser desplazada por las normas autonómicas. 
ción, hasta convertirla en "un mero referente pedagógico"12. Al menos esto refleja aproximadamente la realidad en algunos aspectos ${ }^{13} \mathrm{y}$, en especial, en cuanto a la protección del patrimonio arqueológico frente a las obras. Pese a que cada una de las leyes autonómicas presenta singularidades de fondo y de forma, trataremos, aun reconociendo la inexactitud que conlleva, de homogeneizarlas para exponer el panorama de modo que puedan extraerse los rasgos generales.

\section{Actuaciones arqueológicas previas a obras en zonas con una declaración formal de la existencia de restos arque- ológicos relevantes}

Por lo general, cuando se trata de realizar obras en zonas que las Comunidades Autónomas han declarado BIC o de "interés nacional" o inventariadas o catalogadas formalmente por constar que albergan restos arqueológicos relevantes, las leyes autonómicas suelen exigir directamente la presentación por el promotor de un proyecto arqueológico y, si es autorizado por la Administración cultural, se deberá ejecutar por aquél. Mientras las excavaciones o prospecciones no se ultimen y se ofrezcan sus resultados, no podrán comenzar las obras ni normalmente obtener siquiera la licencia urbanística municipal. En algunas leyes autonómicas (la de Galicia, Andalucía...) ese deber no está impuesto por la ley con carácter general sino que se apodera a la Consejería de Cultura y al planeamiento urbanístico para exigirlo. Sea de una forma o de la otra, se trata de una carga no prevista en la LPHE ni siquiera para las zonas $\mathrm{BIC}$, carga en cuya virtud los promotores, si quieren seguir adelante con las obras, tienen que redactar mediante arqueólogo un proyecto, conseguir autorización de la Administración cultural y ejecutarlo, otra vez, claro está, mediante arqueólogo.

Quede claro que lo que se les exige no es un mero estudio de la incidencia de las obras en los restos sino la redacción y ejecución de una verdadero proyecto arqueológico al que se le da el mismo severo tratamiento que si lo pretendiera hacer motu proprio por su interés científico con todos los rigurosos condicionantes que ello conlle-

${ }^{12}$ J. M. ALEGRE ÁVILA, "Patrimonio histórico, cultura y Estado autonómico", Patrimonio cultural y Derecho, no 5 (2001), p. 159. Además, como explica R. LEÑERO BOHÓRQUEZ en la tesis a las que me vengo refiriendo, el Estado parece "haberse aquietado a esta situación, satisfecho con el papel de inspiración o referente que ha jugado la LPHE". Pero hasta eso se puede perder, si no se ha perdido ya en gran parte, porque "ningún obstáculo jurídico formal impide que el legislador autonómico opte por soluciones divergentes a las asumidas por la LPHE, ante la falta de explicitación de la base competencial en que se fundan sus distintas disposiciones".

${ }^{13}$ Vid. G. BARRERO RODRÍGUEZ, "Las contradicciones entre la ley estatal y las leyes autonómicas en materia de patrimonio histórico y cultural. Sus posibles soluciones en vía normativa", Patrimonio cultural y Derecho, $\mathrm{n}^{\circ} 13$ (2009), pp. 36 y ss. 
va (es necesario acreditar la solvencia científica del investigador responsable, que se cuenta con un equipo adecuado y con financiación suficiente; especificar las técnicas que se emplearán, programar los trabajos, etc.; y, además, presentar al término de los trabajos una memoria científica final con los resultados obtenidos) y con el amplio margen de apreciación que se reconoce a la Administración que no sólo puede denegar la autorización sino someterla a las condiciones que considere oportunas para garantizar su mejor realización ${ }^{14}$.

Partiendo de esa carga que inicialmente se hace recaer sobre el promotor, cuestión diferente es si las leyes autonómicas admiten después alguna forma de compensación o reembolso. A ello nos referiremos más tarde.

\section{Actuaciones arqueológicas previas a obras en zonas en las que sólo se presume la existencia de restos arqueoló- gicos}

Para las obras que se pretenda hacer en terrenos en los que simplemente se presume la existencia de restos arqueológicos de los que, además, claro está, no consta un valor relevante ni su exacta localización, se exige como regla general que el promotor presente previamente un mero estudio sobre la incidencia de las obras proyectadas en los presuntos restos arqueológicos. No es un requisito inocuo porque, como por ejemplo especifica la Ley valenciana de Patrimonio Cultural, tal estudio ha de estar "suscrito por técnico competente" y su realización puede requerir ya excavaciones o prospecciones que deberán ser previamente autorizadas (art. 62.1). En general, lo que con ello se persigue es comprobar si la sospecha o presunción de existencia de restos arqueológicos se confirma o no en la concreta parcela sobre la que se pretende construir.

${ }^{14}$ Argumentadamente, R. LEÑERO BOHÓRQUEZ afirma el carácter discrecional de estas autorizaciones. En la misma línea y admitiendo la posibilidad de imponer condiciones, vid. J. M. ALEGRE ÁVILA, Evolución y régimen jurídico del patrimonio histórico, Ministerio de Cultura, Madrid, 1994, II, pp. 406 y ss., y R. ALONSO IBÁÑEZ, El patrimonio histórico. Destino público y valor cultural, Civitas, Madrid, 1992, p. 367. Parcialmente en contra J. BARCELONA LLOP, "Aspectos del régimen jurídico de las autorizaciones arqueológicas", Revista Aragonesa de Administración Pública, no 21 (2002), pp. 137 a 140, que se inclina por entender que se está ante una discrecionalidad técnica, o sea, ante una potestad reglada mediante conceptos jurídicos indeterminados de carácter técnico. Vid. asimismo F. SAINZ MORENO, "El régimen jurídico del patrimonio arqueológico", formadas internacionales. Arqueología de intervención, Gobierno Vasto, Bilbao, 1992, p. 27. Sea como fuere, no puede negarse un amplio margen de apreciación administrativa que permitiría también imponer condiciones y que limita notablemente el control judicial, como reconoce el propio BARCELONA, idem, p. 140. 
Sobre la base de ese primer estudio, la Administración cultural puede, con amplio margen de apreciación, autorizar sin más las obras o imponer al promotor la redacción y ejecución de un auténtico proyecto de actuación arqueológica. En este segundo supuesto, el promotor se encontrará en una situación prácticamente idéntica a la descrita en el apartado anterior: esa actuación arqueológica, pese a haber sido decidida por la Administración, necesitará la autorización a que están sujetas todas las excavaciones y prospecciones arqueológicas, por lo que de nuevo caerá bajo la discrecionalidad administrativa en cuanto a la forma y extensión de la investigación $^{15}$.

Pero por lo general ello sólo es posible ante zonas para las que, por existir algunos indicios, se han delimitado con precisión por la Administración y han sido declaradas formalmente con este régimen. A veces, incluso, con alguna denominación específica como la de "área de vigilancia arqueológica", "espacios de protección arqueológica", "zona de servidumbre arqueológica", "espacio de interés arqueológico" o similares, y tras un procedimiento que tiende a garantizar la seriedad de la declaración. No obstante, como luego se verá, a veces las leyes autonómicas permiten que sean los planes de urbanismo los que delimiten las zonas sometidas a este régimen.

Explicado que también en estas zonas las leyes autonómicas permiten imponer investigaciones arqueológicas como requisito previo a la obra, veremos después si eso significa que deban financiarlas íntegramente con su patrimonio. Por ahora, nótese que estos regímenes autonómicos comportan: a) la consagración de una carga inexistente en la LPHE; b) no sólo una ampliación del principio de prevención sino también una peculiar aplicación del principio de precaución o cautela porque, a fin de cuentas, se establece un régimen restrictivo basado en meras sospechas sin que exista certidumbre científica sobre los riesgos. Sería al menos de desear que esta sui generis proyección del principio de precaución se rodeara de las mismas garantías que se exigen para la protección del medio ambiente y la salud, ámbitos en los que el principio de precaución tiene su origen y en los que sigue encontrando sus más genuinas aplicaciones.

Aclaremos también que tanto en este caso como en el anterior, y en la línea de lo que antes dijimos al hilo del art. 22.1 LPHE, lo que se impone al promotor de la obra

${ }^{15} \mathrm{Al}$ final es posible que el promotor se vea compelido a realizar más estudios en estas zonas que en aquéllas en las que consta con certeza la existencia de restos. Lo critica I. RODRÍGUEZ TEMIÑO, Arqueología urbana en España, cit., p. 139, en relación con las leyes catalana y andaluza: “... la presunción... de aparición de un yacimiento merece mayor cuidado y tutela ... que su comprobada existencia ...". Además, explica el mismo autor en pp. 150 y ss. que varias leyes autonómicas "han distorsionado el concepto y la finalidad de las zonas de presunción". 
no es estrictamente un deber sino una carga: si no realiza la actuación arqueológica acordada por la Administración y renuncia a emprender la obra que inicialmente pretendía, no estará incurriendo en ninguna ilegalidad ni cabe que la Administración proceda a la ejecución forzosa ${ }^{16}$.

\section{Obras en cuya ejecución se producen hallazgos casuales}

Para el supuesto de que en la obra ya iniciada se produzca un hallazgo casual, las leyes autonómicas permiten a la Administración cultural acordar su suspensión durante un cierto periodo de tiempo sin derecho a indemnización. Va desde diez días (así en la Ley valenciana) a dos meses (como en Castilla-La Mancha o Andalucía) ${ }^{17}$. Durante ese tiempo, o más si es necesario, la Administración puede decidir, si la índole del hallazgo lo aconseja, acometer la actuación arqueológica correspondiente. Pero entonces el proyecto de actuación y su ejecución corresponderán a la propia Administración que asumirá directamente todos los costes y que, además, indemnizará por la interrupción superior al plazo establecido y por los demás daños y perjuicios causados. Ello, salvo que, a la vista del hallazgo, se resuelva calificar los terrenos conforme a alguna de las declaraciones formales a las que nos hemos referido en los apartados anteriores y sin perjuicio de que la Administración consiga que el promotor asuma "voluntariamente" la realización de estas intervenciones de urgencia para evitar más retrasos y problemas. Sirve de referencia para dar una idea de este régimen autonómico el art. 48.2 de la Ley vasca de Patrimonio Cultural:

${ }^{16}$ De esto, sin embargo, se aparta alguna ley autonómica. En concreto, lo hacía la ya derogada Ley de Patrimonio Histórico de Castilla-La Mancha en la redacción que dio a su art. 21.3 la Ley 9/2007: "Cuando un propietario o promotor no iniciara el estudio arqueológico preceptivo o lo suspendiera sin causa justificada, impidiendo en el caso de actuaciones colindantes a otras en las que ya han aparecido restos la realización del estudio en parcelas o solares contiguos, la Consejería... formulará requerimiento para el inicio o reanudación del estudio en el plazo de un mes. Si el propietario o promotor no lo hiciera, o haciéndolo volviera a producirse, sin causa justificada, la interrupción, la Consejería... podrá ejecutar subsidiariamente, a cargo de dicho propietario o promotor, la realización del estudio arqueológico". Pero esta solución no tenía sentido. Si el propietario o promotor decidiera no continuar la actuación arqueológica no podría realizar las obras que pretendía, pero no cabe imponerle coactivamente aquélla. La solución sería servirse del art. 43 LPHE o de precepto autonómico similar y, naturalmente, a costa de la Administración. Y es exactamente eso lo que se acoge en la nueva Ley castellano-manchega 4/2013 de Patrimonio Cultural cuyo art. 54 tiene un contenido igual al del art. 43 LPHE aunque bajo el equívoco rubro de "Ejecución forzosa" que desorienta sobre su significado.

${ }^{17}$ En la Ley 3/2013 de Madrid, la última por ahora de las autonómicas sobre la materia, el plazo es de quince días (art. 31.5); en la Ley de Patrimonio Histórico y Cultural de Extremadura es de veinte días (art. 54.2); en la Ley del Principado de Asturias es de un mes (art. 68.2); etc. Vid. J. ALONSO GARCÍA, "Las cargas arqueológicas...", cit., p. 163. 
"Si el hallazgo ha sido obtenido por... obras de cualquier índole, la Diputación Foral o, en caso de urgencia, los Alcaldes..., podrán ordenar la interrupción inmediata de los trabajos por plazo máximo de quince días. Dicha paralización no comportará derecho a indemnización alguna. En caso de que resulte necesario, la Diputación Foral podrá mantener la suspensión para realizar la actuación arqueológica correspondiente. En este caso, se estará a lo dispuesto en la legislación general sobre responsabilidad de las Administraciones públicas.

Asimismo, la Diputaciones forales asumirán los costes de redacción y ejecución del proyecto arqueológico, salvo que el Gobierno Vasco incoe expediente para calificar o inventariar el bien afectado..." 18 .

Se combinan este tipo de previsiones sobre los hallazgos casuales en obras con preceptos similares al art. 43 LPHE y algunos añadidos. Por ejemplo, dispone el art. 50 de la Ley de Patrimonio Cultural de Cataluña:

"El Departamento de Cultura puede ejecutar directamente las intervenciones arqueológicas que considere oportunas. También las corporaciones locales pueden ejecutarlas en el marco de sus competencias... con la autorización previa del Departamento de Cultura... Estas actuaciones se inspirarán en el principio de mayor economía en los perjuicios que se puedan ocasionar a los particulares. Las indemnizaciones que puedan corresponder se rigen por lo que establece la legislación sobre expropiación forzosa."

Igualmente, art. 55 de la Ley del Patrimonio Histórico de las Islas Baleares: "El consejo insular correspondiente podrá ordenar la ejecución de intervenciones arqueológicas... cuando presuma la existencia de yacimientos o restos... Al efecto de la correspondiente indemnización, regirá lo dispuesto en la legislación vigente sobre expropiación forzosa".

De la combinación de ambos tipos de normas (las de los hallazgos y las que genéricamente permiten a la Administración acordar y realizar por su cuenta actuaciones arqueológicas) lo que se deduce en general es que, ante hallazgos casuales en obras ya iniciadas, el promotor no asume ni la realización ni el coste de la actuación arqueológica que se acuerde sino que, por el contrario, tiene derecho a ser indemnizado por los daños que ello le origine. Sin embargo en las leyes autonómicas este ré-

${ }^{18}$ En general, las leyes autonómicas, aunque a veces con menos claridad, responden a la misma idea. Pudiera ser una excepción la Ley valenciana (art. 63) pero, como se verá, el TSJ de Valencia no lo ha entendido así. 
gimen tiene una aplicación muy inferior a la que resultaba del esquema de la Ley estatal pues sólo quedará para los casos en que ni haya una declaración formal sobre el valor de la zona ni sobre la presunción de existencia de restos arqueológicos ${ }^{19}$.

\section{EN ESPEGIAL, LAS PREVISIONES AUTONÓMICAS DE FI- NANGIAGIÓN PÚBLICA DE LAS ACTUACIONES ARQUEO- LÓGICAS IMPUESTAS A LOS PROMOTORES DE OBRAS}

\section{Ayudas públicas, no indemnizaciones}

Salvo en el caso de los hallazgos casuales en obras, ya hemos visto que cuando se trata de las que se realicen en zonas en las que consta la existencia de restos arqueológicos o en aquéllas en las que fundadamente se presuma su existencia se carga al promotor con la realización de actuaciones arqueológicas: o bien se le imponen meros estudios sobre su incidencia o bien, tras ellos o directamente, se le imponen prospecciones o excavaciones. Así que ya se deduce de lo dicho que será el promotor quien primeramente ha de costear íntegramente todos los gastos que eso comporte y quien, además, sufrirá las consecuencias económicas del retraso que ello suponga.

Pero algunas leyes autonómicas han moderado esta previsión. Lo hacen previendo específicamente ayudas públicas que no tienen la naturaleza de indemnizaciones ni están basadas en la legislación de responsabilidad patrimonial de las Administraciones ni en la expropiatoria. Las leyes autonómicas sólo se refieren a estas instituciones de la responsabilidad y de la expropiación -y no siempre en los mismos términos- respecto a la paralización de obras por hallazgos casuales o cuando se trate de actuaciones arqueológicas al margen de cualquier obra proyectada o emprendida; no cuando la misma ley impone al promotor -o habilita a la Administración a imponer al promotor- la realización de estas actuaciones arqueológicas. Para estos casos par-

\footnotetext{
${ }^{19}$ Lo destaca LEÑERO BOHORQUEZ para la que este régimen tendrá "una aplicación anecdótica tras el advenimiento de la legislación autonómica". Después insiste en que la regulación del hallazgo casual "debe considerarse residual ya que, precisamente, el arsenal de mecanismos de control preventivo que prevé el Derecho autonómico se dirige a impedir o reducir al máximo la posibilidad de que se produzca un hallazgo casual". Y todavía después reitera que "el descubrimiento fortuito constituye... un supuesto no deseado ... una anormalidad o fallo en la gestión de la protección...". Vid también J. BERMÚdEZZ SÁNCHEZ, "Mecanismos de financiación...", p. 124. Ejemplifica este fenómeno la STSJ de Baleares 626/2010, de 29 de junio, que luego analizaremos. En cualquier caso, además, es fácil para la Administración evitar la aplicación de este régimen de los hallazgos casuales mediante declaraciones extensas, a priori o incluso a posteriori, sobre el valor presunto de los terrenos.
} 
ten de que el promotor, al que se impone la carga, ha de sufrir sus consecuencias patrimoniales. Lo que se prevé, si acaso, son ayudas públicas ${ }^{20}$.

\section{La completa financiación pública}

La solución más favorable a los promotores es la que parece acoger la Ley de Patrimonio Histórico de Canarias. Su art. 65.3 dispone: "En los casos en que una excavación arqueológica se haga necesaria, su financiación correrá a cargo del promotor de las actuaciones afectantes cuando se trate de obras promovidas o financiadas por entidades públicas. En caso contrario, se costeará por la Administración que haya ordenado la intervención". O sea, que si se trata de un promotor privado es la Administración la que ha de financiar en su totalidad la excavación arqueológica ${ }^{21}$.

\section{La exclusión de toda cofinanciación pública}

En el extremo opuesto se sitúa, por ejemplo, la Ley de Patrimonio Histórico de Andalucía. Además del estudio previo sobre la incidencia arqueológica de las

${ }^{20}$ Entiendo que, dentro del concepto legal de subvención que acoge la Ley General de Subvenciones, las que se prevén por la realización de estas actuaciones arqueológicas entrarán de ordinario en la categoría más específica de las primas. Vid. A. BUENO ARMIJO, El reintegro de subvenciones de la Unión Europea, Instituto Andaluz de Administración Pública, Sevilla, 2011, pp. 70 y ss. No es óbice a ello el que con tales subvenciones (propiamente primas) no se trate de fomentar una actividad libre sino que se parta de un deber del administrado (en nuestro caso, más exactamente, una carga) de realizar la actividad para la que se da la ayuda. Y es que es posible y hasta frecuente la existencia de subvenciones que no entran exactamente en la actividad de fomento sino que tratan de sufragar o paliar los costes que para los administrados tiene el cumplimiento de ciertos deberes. En tales casos, como explica el mismo BUENO ARMIJO, pp. 38-39, las ayudas tendrán una apariencia y un cierto carácter indemnizatorio, pero no son realmente indemnizaciones.

${ }^{21}$ Aun así, digamos que el precepto no es del todo claro ni, en cualquier caso, exime al promotor de todos los gastos porque nótese que se refiere específicamente a las "excavaciones". Por lo pronto, el apartado 1 de ese mismo art. 65 impone al promotor de obras aportar un estudio sobre la incidencia de la obra en los valores arqueológicos y tal estudio sí que ha de ser sufragado por él. Y, por otra parte, su apartado 2 dice que la Administración, a la vista del anterior estudio, "podrá disponer la realización de prospecciones o sondeos en orden a evaluar los efectos de la intervención, así como también determinar las posibles medidas protectoras a adoptar durante las obras, trazados alternativos y demás condiciones dirigidos a la salvaguarda del yacimiento". Nótese que sólo habla de "prospecciones y sondeos" y que su finalidad no es nunca la de estudiar y documentar en su plenitud los restos sino sólo evaluar los efectos de las obras y, si acaso, preservar los restos de la destrucción imponiendo las condiciones de la obra. Así que cabe entender que esas "prospecciones y sondeos" no están incluidos en el apartado 3 que sólo se refiere a "excavaciones". Pero, incluso aunque se opte por una interpretación restrictiva del art. 65.3, supone, como decíamos, la solución más favorable al promotor de las distintas leyes autonómicas. 
obras proyectadas, cuando es necesario, las excavaciones, prospecciones o sondeos que la Administración ordene realizar deben ser asumidas y costeadas íntegramente por el promotor que no tendrá derecho a ninguna compensación. Además, estos gastos no tienen límite cuantitativo ni absoluto ni porcentual. El único límite es el art. 59.2: "La actividad arqueológica... se extenderá hasta el límite del aprovechamiento urbanístico que la persona o entidad promotora tuviera atribuido sobre el subsuelo". Pero se trata de un límite físico o espacial, no económico. Lo corrobora el siguiente apartado 3 según el cual la Consejería, por razones de interés científico o de protección del patrimonio arqueológico, puede "ampliar la extensión de la actividad arqueológica, financiando el coste añadido que ello suponga”. Por tanto, sólo hay financiación pública en cuanto se extiendan las actuaciones arqueológicas más allá de donde alcanza físicamente el aprovechamiento urbanístico del propietario; para todas aquellas actuaciones incluidas en el espacio hasta donde éste llega, el promotor debe afrontar y costear todas las que se le impongan. Y, a diferencia de lo que hemos visto en la ley canaria -y de lo que veremos en otras leyes autonómicas-, aquí no se distingue entre promotores públicos y privados porque a ambos se impone por igual la realización y financiación de las actuaciones arqueológicas.

\section{Diversas soluciones intermedias de cofinanciación públi- ca parcial}

Lo más frecuente es que las leyes autonómicas se sitúen en un punto intermedio por la vía de prever alguna cofinanciación pública parcial ${ }^{22}$, aunque las más de las veces con notable ambigüedad.

a) El modelo más claro lo ofrece la Ley vasca de Patrimonio Cultural. Su art. 45.5 es del siguiente tenor:

"En los casos en que la actuación arqueológica se haga necesaria como consecuencia de cualquier tipo de obras que afecten a zonas o bienes arqueológicos calificados y a los inventariados, el promotor deberá presentar el correspondiente proyecto arqueológico ante la Diputación Foral correspondiente para su aprobación previa a la ejecución de aquéllas. Su financiación correrá a cargo del titular de las actuaciones afectantes en el caso de que se trate de entidades de derecho público. En caso contrario, la Diputación Foral correspondiente participará en la asunción de los gastos mediante la concesión de ayudas en los términos que se fijen reglamentariamente a no ser que ejecute directamente el proyecto que es-

\footnotetext{
${ }^{22}$ Vid. J. BERMÚDEZ SÁNCHEZ, El derecho de propiedad..., cit., pp. 122 a 124 y 129-130.
} 
time necesario. En todo caso, la Diputación estará obligada a satisfacer el 50 por 100 del monto total que suponga la actuación arqueológica".

Después, el art. 49.2 declara de aplicación este "régimen subvencional" -así lo denomina- a las obras en terrenos en que simplemente se presuma la existencia de restos arqueológicos.

Quedan varios aspectos abiertos e indeterminados tanto por la remisión reglamentaria como por la posibilidad de que la Administración "ejecute directamente el proyecto que estime necesario". Pero al menos es claro que, aunque sea el promotor particular quien debe encargar y pagar el proyecto arqueológico así como quien debe afrontar y costear como actividad propia su ejecución, tiene derecho a que, en concepto de subvención o "ayuda", se le reembolse como mínimo el $50 \%$.

b) Más imprecisa es la Ley de Patrimonio Cultural de Galicia. Su art. 63, al regular las "intervenciones arqueológicas por obras en conjuntos históricos, zonas arqueológicas o yacimientos catalogados o inventariados", dispone en su apartado 2:

"Si se trata de un particular, la Consellería de Cultura colaborará en la financiación del coste de la ejecución del proyecto. Si el promotor de la obra es una Administración pública o un concesionario, el coste de las intervenciones arqueológicas será asumido íntegramente por la entidad promotora".

Pese a que el precepto se expresa imperativamente, no se dice en cuánto ha de colaborar la Consejería y tampoco hay una remisión al reglamento. Así que, en principio, respetaría este mandato una ayuda pública ínfima. Además, esta Ley no contiene una previsión similar para los casos en que las actuaciones arqueológicas se hayan de realizar en terrenos donde simplemente haya una presunción de restos arqueológicos, supuesto en el que esta Ley también permite a la Administración "ordenar algún tipo de intervención arqueológica". Pero resulta lógico pensar que si se prevé colaboración pública en la financiación de obras en los terrenos de más valor con mayor razón debe haberla cuando se trata de terrenos en los que no hay certeza total de la existencia de restos. Después veremos cómo ha interpretado esta norma el TSJ de Galicia.

c) La Ley balear de Patrimonio Histórico establece en su art. 59.3 una previsión análoga a la vista en la Ley gallega. Al regular en general todas las intervenciones arqueológicas previas que se impongan a los promotores de obras en cualesquiera espacios de interés arqueológico, dispone:

"Si se trata de un particular, el consejo insular podrá colaborar en la financiación del coste de la ejecución del proyecto. Si el promotor de la obra es una 
Administración pública o concesionario, el coste de las intervenciones arqueológicas o paleontológicas será asumido íntegramente por la entidad promotora".

Pero en este caso el precepto, que dice "podrá colaborar", no expresa un mandato sino que presenta la financiación pública, de cuya cuantía nada se dice, como algo meramente facultativo. Veremos después que la STSJ de Baleares 626/2010 ha subrayado ese carácter potestativo.

d) Aparentemente también es similar la Ley de Patrimonio Cultural de la Comunidad Valenciana cuyo art. 63.3 establece: "La Generalitat participará en la financiación de las mencionadas actuaciones, según los créditos que al efecto se consignen en la Ley de Presupuestos".

No es un precepto facultativo sino imperativo ("participará", dice). Pero su significado se oscurece, no ya sólo por su remisión a las leyes de presupuestos, que le resta fuerza, sino sobre todo porque sorprendentemente se incluye en el artículo dedicado a actuaciones arqueológicas en obras ya iniciadas en las que se produzcan hallazgos casuales. O sea, que está imponiendo una cofinanciación pública para un caso en el que las demás leyes autonómicas prevén, no ya esas meras ayudas a posteriori, sino la asunción íntegra por la Administración de las actuaciones arqueológicas. Por el contrario, cuando su art. 62 se ocupa de las actuaciones arqueológicas previas a la ejecución de las obras, establece que será el promotor quien asumirá las actuaciones arqueológicas y no prevé ninguna ayuda pública. Por tanto, en realidad, esta Ley valenciana consagra un régimen mucho más gravoso que el de las otras leyes autonómicas vistas, un régimen que carga sobre el promotor todas las intervenciones, incluso las realizadas a raíz de hallazgos casuales en terrenos sin ninguna protección previa, con la única matización en este caso de contar con una parcial financiación pública de alcance indeterminado y reconocer derecho a indemnización si la suspensión de las obras se prorroga.

Pero esta interpretación no es la que parece haber acogido el TSJ de Valencia, como demuestra su sentencia 941/2006, de 17 de mayo. Parte esta sentencia de que en el caso se trataba de obras en las que, como consecuencia de un hallazgo casual, se ordenó una actuación arqueológica, y no, como pretendía la Generalidad, de una intervención preventiva en terrenos en los que se presumía de antemano la existencia de restos arqueológico. Por eso declara que es de aplicación el art. 63, y no el 62, de la Ley autonómica. Con esa premisa condena a pagar la totalidad de los gastos arqueológicos más una indemnización por el retraso de las obras, todo ello como un supuesto puro de responsabilidad patrimonial de la Administración y sin citar siquiera el art. 63.3. O sea, reconduce a la responsabilidad de la Administración lo que la Ley valenciana establece como un deber legal que ha de soportar el promotor al que, a lo sumo, se le da derecho a recibir alguna ayuda pública. Si esta STSJ de Valencia fuese correcta, habría que entender que la Ley valenciana, aunque lo exprese mal, 
establece para los hallazgos casuales en obras el mismo régimen de la LPHE y de las demás leyes autonómicas, esto es, que en tales hipótesis las actuaciones arqueológicas debe costearlas totalmente la Administración que además debe indemnizar por la interrupción de las obras a partir de un cierto plazo; y que, por el contrario, el art. 63.3, aunque erróneamente ubicado, consagra un mandato de ayudas públicas para los supuestos de intervenciones arqueológicas preventivas en espacios en los que conste o se presuma de antemano la existencia de restos, un mandato similar al visto en las leyes anteriores.

e) Una variante de este sistema de cofinanciación pública parcial consagra el art. 84 de la Ley cántabra de Patrimonio Cultural. Tras proclamar que "en el caso de que la Consejería... estime necesaria la realización de una actuación arqueológica, el propietario o promotor de la obra deberá asumir la financiación de los costes de la intervención", el apartado 6 establece: "Si se tratase de un particular, la Administración ayudará a financiar la actuación arqueológica si ésta supera el dos por ciento del presupuesto global de la obra. Si el promotor de la obra es una Administración pública o concesionario, el coste de las intervenciones arqueológicas será asumido íntegramente por la entidad promotora". La misma regla se aplica respecto a los gastos del seguimiento arqueológico que se requiere para las obras que afecten a espacios en los que se presuma la existencia de restos $\left(\right.$ art. 83.2) ${ }^{23}$.

\section{Precisiones sobre los retrasos, sobre los promotores pú- blicos y sobre los gastos de redacción del proyecto arque- ológico}

Basta pasar revista a las leyes autonómicas que hemos escogido en este sondeo para observar, aun dentro de la imprecisión de cada una de ellas, las diferencias notables que presentan entre sí y, aún más, con la LPHE. Pero apuntemos ahora, además, algunos aspectos problemáticos concretos.

${ }^{23}$ Indudablemente aquí hay un mandato: "ayudará", dice el precepto. E indudable es asimismo que el mandato sólo opera cuando el coste arqueológico supere el indicado 2\%. Pero, además de las dificultades para precisar qué gastos se incluyen en uno y otro concepto, lo que no se dice es cuál ha de ser la cuantía de la ayuda pública. Quizá quepa interpretar que habrá de cubrir todo el exceso de ese $2 \%$ y quizá sea eso lo que se quiso decir, en cuyo caso el mandato tendría perfiles nítidos. Pero el tenor literal permite también entender que el mandato se satisfaría con cualquier ayuda pública, aunque no cubriera todo ese exceso y aunque fuese ínfima. Con todo, no son esas las únicas dudas que suscita esta norma pues el reproducido apartado 6 se contiene en un artículo intitulado "suspensión de obras" y cabría sostener, por tanto, que no incluye los supuestos en los que las actuaciones arqueológicas se deben realizar antes de su inicio. Pese a ello, aceptemos, pues parece lo más razonable, que, aunque mal situado, ese precepto establece una obligación de cofinanciación de todos los trabajos arqueológicos que deba realizar el promotor de las obras. 
Por lo pronto, en ninguna de ellas se prevé una duración máxima para las intervenciones arqueológicas que se impongan ni compensación alguna por el tiempo de retraso para las obras que ello entrañe. Sí las hay para cuando tales intervenciones son acordadas con ocasión de un hallazgo casual en unas obras ya iniciadas, pero no cuando son previas a su ejecución. Sin embargo, ello comporta la paralización de inversiones y muchos perjuicios. Se supone, parece, que ello debe sufrirlo el promotor sin límite, acaso porque se piense que, como se está en terrenos que contaban de antemano con una conocida protección, a diferencia de que sucede con los hallazgos casuales, el promotor debía contar con ello.

En segundo lugar, cuando se prevé una financiación pública total o parcial, las leyes autonómicas siempre excluyen de una u otra forma a los promotores públicos. No todas lo hacen de la misma forma ("entidades públicas", "entidades de derecho público", "Administración pública o concesionario"), pero, en general, además de que pueda dudarse de la justificación material de tal exclusión en todos los casos, suscitan la duda de lo que haya de incluirse en tal concepto; por sólo poner el ejemplo más frecuente, una junta de compensación podría ser considerada una entidad de Derecho público que quedaría excluida hasta de esa cofinanciación pública parcial haciendo recaer todos los gastos sobre los propietarios que la componen sin reembolso alguno, lo que es de justicia y racionalidad discutibles. Lo cierto es que algunas sentencias han acogido reclamaciones de juntas de compensación sin plantearse su exclusión por tratarse de una entidad de Derecho público ${ }^{24}$.

Y nótese por último que la financiación pública suele referirse a los gastos de ejecución del proyecto arqueológico, no a su misma redacción, con la que parece que en todo caso ha de pechar el promotor en su totalidad y sin compensación de ningún género ${ }^{25}$.

\section{Pronunciamientos judiciales}

Los tribunales se han enfrentado en algunos casos a reclamaciones por actuaciones arqueológicas. No muchas veces para lo que cabría esperar y sin que, salvo error, hayan llegado al Tribunal Supremo que se ha ocupado de temas próximos, pero no exactamente de los que nos ocupan. Además, las escasas sentencias de los Tribunales Superiores de Justicia no se sitúan en la misma línea. Me limitaré a exponer las de dos Tribunales Superiores de Justicia que lo han hecho más reciente y detenidamente.

24 Así, SSTSJ de Galicia 907/2004, de 9 de diciembre, y 529/2013, de 20 de junio.

25 STSJ de Galicia de 17 de septiembre de 2009. 
El TSJ de Galicia se ha pronunciado al menos en doce sentencias sobre lo que nos ocupa ${ }^{26}$. En esencia, se pueden sintetizar así:

- En todos los casos condenan a la Xunta a pagar los gastos arqueológicos. Con frecuencia han condenado a pagar todos esos gastos íntegramente ${ }^{27}$.

- El fundamento legal de estas SSTSJ es el ya antes citado art. 63.2 de la Ley gallega, esto es, el que sin más precisiones dice que la Consellería de Cultura colaborará en la financiación del coste de la ejecución del proyecto. Alguna de ellas (por ejemplo, la 621/2002, de 24 de abril) aclara expresamente que no se trata de un supuesto de responsabilidad patrimonial de la Administración; y otra (la 135/2009) afirma que esa parte de financiación pública tiene naturaleza de subvención. Pero, pese a ello y pese a la imprecisión del art. 63.2 de la Ley autonómica, que tampoco contiene una remisión reglamentaria, estas sentencias afirman reiteradamente que "sus términos indiscutiblemente imperativos impiden aceptar que se trate de una previsión legal de colaboración voluntaria o dependiente de partidas presupuestarias" y que "la ausencia de un desarrollo reglamentario en la materia no puede actuar en perjuicio del particular ni servir de amparo a aquellas limitaciones" presupuestarias.

- Junto a ese fundamento legal, se arguye también repetidamente una justificación material: la compensación pública total "conecta con una elemental exi-

${ }^{26}$ SSTSJ de Galicia 1887/2001, de 28 de diciembre; 612/2002, de 18 de abril; 621/2002, de 24 de abril; 907/2004, de 9 de diciembre; 561/2006, de 7 de junio; 1022/2007, de 29 de noviembre; $21 / 2008$, de 16 de enero; 135/2009, de 12 de febrero; $157 / 2012$, de 16 de febrero; 529/2013, de 20 de junio; 616/2013, de 18 de julio; y 392/2014, de 30 de abril. No todas razonan exactamente igual. Además, la primera de ella se refiere a unos hechos anteriores a la vigencia de la Ley autonómica de patrimonio. Las últimas son más confusas por la interferencia de ciertas Órdenes que preveían específicas subvenciones. Tampoco siempre dan todos los datos necesarios, especialmente en relación a las declaraciones previas recaídas respecto al valor y protección arqueológica de los terrenos. Pero, incluso así, tienen un fondo común inequívoco que es el que hay que destacar y aprehender. Quizás la sentencia STSJ 157/2012, de 16 de febrero, sintetice mejor esta jurisprudencia.

${ }^{27}$ Constituye excepción la sentencia 21/2008, de 16 de enero, en la que sólo hay una condena parcial. Pero está más bien motivada por problemas de prueba y la misma sentencia aclara que lo hace atendiendo a las singularidades del caso y por razones de equidad: "Su concreta fijación, en el supuesto que nos ocupa, y sin que sirva de precedente, se hace por el $50 \%$... por lo que procede una solución equitativa". En efecto, no creó precedente y sentencias posteriores volvieron a condenar a pagar todos los gastos arqueológicos. No obstante, las más recientes admiten sólo compensaciones parciales de acuerdo con ciertas Órdenes que establecieron las bases reguladoras para la concesión de estas ayudas, Órdenes a las que no se ajustaron los solicitantes y que, como aclara la STSJ 529/2013, "no son objeto de impugnación indirecta". 
gencia de que lo que constituye un beneficio colectivo no se apoye en el mantenimiento de un injustificado perjuicio para un particular". Tal vez sea esto lo que realmente inspire estas sentencias y lo que llevó a acoger una interpretación tan discutible del art. 63.2 de la Ley gallega.

A fin de cuentas, esta línea del TSJ gallego supone que, aunque se parta de que es el promotor quien inicialmente afronta e incurre en los gastos por las intervenciones arqueológicas previas a las obras que proyecta, finalmente no sufrirá ninguno de esos gastos pues, a la postre, recaerán en su totalidad sobre la Administración que tendrá que otorgar una subvención igual a toda su cuantía.

En realidad hay más todavía, pues en dos de esas sentencias se condena a la Xunta además por el retraso que las actuaciones arqueológicas comportaron. En concreto, la 612/2002 condenó al pago del interés legal del dinero de la inversión mientras se ejecutaban las actuaciones y la sentencia 157/2012 condenó a compensar por ese tiempo que "entrañó una "inversión que permaneció improductiva". Y ello pese a que en ninguna quede claro el fundamento legal de esta condena que, desde luego, no se encuentra ya de ninguna forma en el art. 63.2 de la Ley gallega.

Frente a lo anterior postura, es particularmente ilustrativa la STSJ de las Islas Baleares 626/2010, de 29 de junio ${ }^{28}$.

Además de excluir la indemnización por pérdida del aprovechamiento urbanístico, que no es lo que nos ocupa, desestima la pretensión indemnizatoria respecto a los daños derivados de las intervención arqueológica que el promotor articuló como una acción de responsabilidad patrimonial de la Administración por funcionamiento normal: el actor, aclara la sentencia, "no discute la procedencia de la protección del patrimonio arqueológico, pero entiende que no tiene la obligación de soportar individualmente los perjuicios que se le han irrogado... por el funcionamiento normal de la Administración". Lo que se discute es sólo si debe sufrir individualmente los gastos de las actuaciones o si deben recaer sobre "la colectividad a quien beneficia esa protección de los restos arqueológicos”. La Administración había aportado 11.000 euros peros los gastos arqueológicos y los perjuicios por el retraso en las obras eran de algo más de un millón de euros. El Tribunal, como el demandante, enfoca la cuestión desde el punto de vista de la responsabilidad patrimonial de la Administración. En concreto, entiende que no se da la antijuridicidad del daño porque el promotor tiene el deber legal de soportarlo. Es así, razona la sentencia, porque las obras se realizaban en una zona de interés ar-

${ }^{28}$ Vid. P. OLLER VIVES, "La indemnización por excavaciones arqueológicas. Comentario a la sentencia del Tribunal Superior de Justicia de las Islas Baleares de 29 de junio de 2010", Patrimonio cultural y Derecho", no 15 (2011), pp. 410 y ss. 
queológico, resultando por ello aplicable el art. 59 de la Ley autonómica del Patrimonio Histórico, y no el art. 55 de la misma Ley (antes transcrito), similar al art. 43 LPHE sobre intervenciones arqueológicas realizadas al margen de obras por iniciativa de la Administración, y que, como éste, acaba por remitir lo relativo a la "correspondiente indemnización” a lo que establezca la legislación de expropiación forzosa:

"La mera lectura de los preceptos... determina que el precepto aplicable es el 59 y no el $55 . .$. ya que este último se refiere a las intervenciones arqueológicas ordenadas directamente por (la Administración cultural), diferentes de aquéllas que pueden exigirse cuando el promotor decide voluntariamente, en el ámbito de su actuación empresarial, llevar a cabo obras o intervenciones en espacios de interés arqueológico, sin que la iniciativa de la actuación en ese ámbito sea de la Administración competente sino del administrado, por lo que el régimen jurídico del resarcimiento de los gastos es el establecido por este artículo (el 59) y no el de la legislación de expropiación forzosa".

Pero lo cierto es que ese art. 59, que la sentencia considera de aplicación al caso, aunque efectivamente permite imponer al promotor de las obras "la realización y la ejecución de una intervención arqueológica”, establece en su apartado 3, como ya recordamos antes, que en estos casos "el Consejo Insular podrá colaborar en la financiación". Y para el TSJ balear esto significa que la colaboración está "configurada con carácter potestativo" y satisfecha con los 11.000 entregados, aunque sólo cubrieran una ínfima parte de los gastos. Por ello la sentencia concluye:

“... no existió daño o lesión antijurídica ... por los gastos derivados de la intervención arqueológica, ya que el promotor está obligado a sufragarlos cuando acometa obras en los lugares calificados de espacios de interés arqueológico, existiendo el deber jurídico de soportar el gasto que suponga, siendo la obligación del Consejo Insular de contribuir a los mismos potestativa".

Por tanto, ni hay responsabilidad patrimonial de la Administración, porque el promotor tiene el deber legal de soportar el daño, ni éste tiene derecho a obtener ninguna financiación pública porque la ley sólo la ha previsto como algo eventual, potestativo y discrecional.

\section{LA AGRAVACIÓN DE LA SITUACIÓN EN LOS PLANES UR- BANÍSTICOS}

Por si el panorama legal no fuese suficientemente complejo y además de que en ocasiones los reglamentos han impuesto nuevos deberes sin base legal, también los planes de urbanismo han agravado la situación. Es cierto que muchas las leyes auto- 
nómicas hacen remisiones a los planes urbanísticos ${ }^{29}$. Pero es que, hasta sin remisiones legales de esa índole o superándolas, los planes han construido por su cuenta regímenes variados y gravosos hasta la exasperación ${ }^{30}$.

Sirvámonos del ejemplo del PGOU de Córdoba ${ }^{31}$. Ni en la actual Ley de Patrimonio Histórico de Andalucía de 2007 ni en la anterior de 1991, que era la vigente cuando se aprobó este plan, se permite ni se permitía que los planes aumentaran las zonas BIC ni las de servidumbre arqueológica. Éstas tienen que ser declaradas y delimitadas formalmente por la Junta de Andalucía tras un procedimiento que garantiza la seriedad de la declaración y los derechos de defensa. Se apodera a los planes

${ }^{29}$ Entre las más amplias, cabe citar la del art. 65 de la Ley canaria y la del art. 58.3 de la Ley valenciana. Según el primero basta que un yacimiento arqueológico esté reconocido en un "instrumento de planeamiento urbanístico", aunque no tenga ninguna otra declaración, para que el terreno se someta a todo el régimen preventivo que hemos descrito. El segundo permite al planeamiento urbanístico delimitar las áreas que "puedan contener restos arqueológicos" y a las que se aplicará el régimen previsto para las "áreas de vigilancia arqueológica". Todo esto hurta hasta las garantías que comporta el procedimiento para declarar una zona BIC o con alguna otra de las calificaciones formales previstas por las leyes, aunque, al menos, el régimen de deberes materiales y económicos sí sea el establecido por la ley. Vid. J. BERMÚDEZ SÁNCHEZ, El derecho de propiedad..., cit., pp. 76 y 118.

${ }^{30}$ Tal vez esto tenga su origen en que antes de la aprobación de la LPHE, la legislación de patrimonio cultural sí que presentaba una gran laguna respecto a las actuaciones preventivas frente a la realización de obras. Según I. RODRÍGUEZ TEMIÑO, Arqueología urbana ..., cit., pp. 50, 51, 128-130, 164 y ss., ello propició que los planes de urbanismo asumieran como función propia construir un régimen de protección arqueológica basado en la financiación privada. Acaso este régimen praeter legem pudiera aceptarse entonces por más que parezca dudoso que respetase la reserva de ley y que encontrara base suficiente en las leyes de urbanismo de la época. El mismo RODRÍGUEZ TEMIÑO, p. 154, habla de "una suerte de chantaje", de la conciencia de "haber traspasado el borde mismo de la legalidad" y de continuar en esa línea "porque los promotores aceptaron de mejor o peor grado esta nueva carga y no plantearon una batalla jurídica seria". Sobre esta aceptación por los promotores para evitar retrasos vid. también pp. 51 y 61. Pero da la impresión de que aquella práctica se ha mantenido, incluso alentada por la Administración cultural autonómica, como si siguiera sin haber una legislación -estatal y sobre todo autonómica- que sí que regula todo eso y como si pudieran continuar estableciendo un completo régimen de arqueología preventiva paralelo al legal. Ahora, creo, ya no es sólo praeter legem sino a veces contra legem y, en cualquier caso, fuente de duplicidades, confusión y opacidad.

${ }^{31}$ Lo analiza críticamente I. RODRÍGUEZ TEMIÑO, Arqueología urbana ..., cit., pp. 186 a 192. Antes y después se ocupa de otros planes. Sobre el planeamiento en Madrid, vid. A. GALLEGO ANABITARTE, "Arqueología y Derecho. Hallazgos, jurisprudencia, legislación, carta arqueológica y planeamiento", Revista de Derecho Urbanístico y Medio Ambiente, no 200 (2003), en especial pp. 111 y ss. El de Ávila lo expone J. BERMÚDEZ SÁNCHEZ, El derecho de propiedad..., cit., pp. 119 a 121 y 124 . 
urbanísticos sólo para concretar, dentro de esas zonas, cuándo será necesaria la realización de actividades arqueológicas previas a las obras o medidas específicas de protección [arts. 31.1.g) y 59.1 de la Ley actual y art. 49.1 de la Ley de 1991], no para que establezcan esas zonas por sí mismos cuando lo juzguen conveniente ni para inventarse un régimen extra legem. Pero lo cierto es que ese Plan de Córdoba hace una zonificación arqueológica de todo el término municipal con tres tipos de terrenos, A, $\mathrm{B}$ y $\mathrm{C}$, que poco tienen que ver con las clasificaciones de la legislación de patrimonio histórico estatal o autonómica.

Las Zonas tipo A son las más protegidas. Allí están los conjuntos y yacimientos arqueológicos declarados BIC. Pero junto a ellos se incluyen también, entre otros, los "yacimientos arqueológicos sin declaración legal expresa, aunque sí recomendada la de zona o yacimiento arqueológico" (sic). Aunque el final sea incomprensible, sí queda claro que se les da trato de BIC a los que no lo son ni se ha incoado ningún procedimiento para ello si se ha "recomendado" aunque no se acierte a saber cómo pueden sustituirse las garantías de un procedimiento de declaración de BIC por una extraña recomendación de no se sabe quién y por ignotos criterios.

Las Zonas tipo B son las muy extensas que específicamente enumera el plan sin mayores explicaciones. No se dice ni se sabe cuál es su interés. Qué hay en ellas o qué se espera que haya es un enigma que no despeja el PGOU, que tampoco da ninguna idea de los criterios seguidos para calificar así a la mayoría de las zonas de expansión de la ciudad. En cualquier caso, ni están declaradas zonas arqueológicas conforme a la legislación estatal ni autonómica ni tienen que ser objeto de inscripción específica en el catálogo ni estar declaradas zona de servidumbre arqueológica. Son sencillamente las que, al margen de todas esas calificaciones legales, el PGOU decide calificar así. Y a éstas zonas $\mathrm{B}$ se las somete a un régimen extremadamente riguroso que, muy elementalmente, puede resumirse así: en terrenos para los que las leyes estatal y autonómica permiten obras sin autorización ni comunicación previa, el PGOU impone dos autorizaciones (una autonómica y otra municipal) y, además, dos comunicaciones previas al comienzo de las actuaciones autorizadas; donde las obras se realizarían en principio (salvo hallazgo) sin arqueólogos, el PGOU impone contratar un equipo de ellos que actuarán bajo la supervisión de dos arqueólogos inspectores (uno de la Consejería y otro del Ayuntamiento); donde no habría deber de realizar intervenciones arqueológicas (salvo hallazgo), aquí se imponen con carácter previo las que la Consejería o el Ayuntamiento entiendan convenientes durante el tiempo que juzguen oportuno y a costa del promotor; donde no habría ninguna obligación similar, aquí se impone una memoria preliminar, un informe técnico preliminar, una memoria final y, si así se decide, informes técnicos parciales... Todo según decidan con amplia discrecionalidad la Consejería o el Ayuntamiento, y siempre a costa del promotor, en un proceso complejo que puede alargarse indefinidamente y en el que hasta los más avezados acaban desorientados. 
Las Zonas tipo C sí aparecen definidas en el PGOU: son aquéllas "donde, aun sin confirmar la existencia de un yacimiento, algún vestigio no definitorio externo, la proximidad a un yacimiento arqueológico o cualquier referencia bibliográfica pudiese indicar la existencia de restos arqueológicos de interés y se considere necesario adoptar medidas precautorias". O sea, que basta para imponer este régimen restrictivo que haya algún libro o artículo que entienda que puede haber allí algo para que la Administración decida que hay que adoptar medidas precautorias a costa del propietario; todo ello sin que se haya procedido a declarar a los terrenos Zona Arqueológica o de Servidumbre Arqueológica o se haya comenzado el procedimiento para tal declaración; es más, se parte de que los terrenos no reúnen los requisitos para ello pues de lo contrario estarían clasificados como Zona A. Pero el régimen que el PGOU establece para estas Zonas tipo C recuerda al que la legislación andaluza prevé para las zonas de servidumbre arqueológica, sólo que agravado: "Cualquier actuación sometida a licencia que conlleve una remoción de terrenos dentro de estas Zonas deberá contar con un Informe Urbanístico de carácter arqueológico previo a la concesión de la misma". Además, todas las obras o remoción de terrenos han de realizarse con "supervisión arqueológica simultánea a todo movimiento de tierras estando prohibido que éstos se realicen sin el control de un técnico arqueólogo".

No creo, desde luego, que el caso del PGOU de Córdoba sea una excepción aislada. De hecho, al parecer, en buena parte sus previsiones se introdujeron de acuerdo con la Consejería de Cultura. Y no podrá negarse que este plan y otros similares instauran un sistema extremadamente protector del patrimonio arqueológico. Pero las cargas que impone no sólo no parecen tener fundamento legal sino que resultan prima facie contrarias a la ley, por no entrar a juzgar su proporcionalidad y racionalidad. Pese a ello, en el mare magnum creado por la misma legislación y el planeamiento, aumentado por la confusa práctica administrativa, todo esto pasa como expresión de unos deberes que han de soportarse sin compensación alguna ni por los gastos que generan ni por los retrasos que entrañan. Naturalmente no debe ser asi ${ }^{32}$.

Por otra parte, todo este régimen -no sólo el que introduzcan los planes sino el que directamente establecen las leyes autonómicas- puede propiciar que no se utilice lo que en principio sería el instrumento urbanístico normal y preferente de protec-

${ }^{32}$ Radical es a este respecto J. BERMÚDEZ SÁNCHEZ, El derecho de propiedad..., cit., pp. 109110, para quien el mero hecho de someter a autorización cultural la realización de obras en zonas de protección arqueológica delimitadas sólo por el planeamiento urbanístico no respeta la reserva de ley y da derecho a indemnización por el retraso que comporta en la iniciación de las obras. Con mayor razón, cuando impone realizar intervenciones arqueológicas previas; ibídem, pp. 160-161. Sobre si debe indemnizar la Administración municipal o la autonómica, pp. 172-173. 
ción del patrimonio arqueológico ${ }^{33}$ : la calificación como suelo no urbanizable especialmente protegido de los terrenos de valor arqueológico. En vez de ello, puede resultar tentador declararlos urbanizables para así garantizarse la financiación privada de las investigaciones arqueológicas.

\section{VALORACIÓN Y PROPUESTA DE REFORMA}

Prescindiendo de los excesos de las normas reglamentarias y de los planes de urbanismo, hay que concluir que las leyes autonómicas han consagrado cargas de los promotores de obras por completo desconocidas en la LPHE que no prevé nada similar ni siquiera para las zonas arqueológicas BIC. Cargas en cuya virtud, si quieren ejecutar su proyecto en zonas en las que conste o se presuma la existencia de restos, han de afrontar y sufragar actuaciones arqueológicas en las que, además, se les da el mismo severo tratamiento que a quien pretende acometer una investigación por su propio interés científico, lo que agrava y alarga su situación. No se trata sólo de imponerles que no dañen el patrimonio arqueológico sino de que contribuyan positivamente a su investigación. Expresivamente se ha llegado a ver en todo esto una especie de mecenas a la fuerza ${ }^{34}$. Y no anda descaminada la STSJ de Andalucía, Sevilla, de 29 de abril de 2002, cuando califica a estas actuaciones arqueológicas del promotor como "prestación personal obligatoria", esto es, aquéllas a las que, junto a los tributos con los que guardan proximidad, se refiere el art. $31.3 \mathrm{CE}$. Todo ello incluso sin límites cuantitativos. Desde el punto de vista de la responsabilidad patrimonial

${ }^{33}$ La Ley del Suelo de 1998 se refería específicamente a los "valores arqueológicos" como fundamento suficiente para esta calificación (art. 9.1). Y no sólo cuando tuvieran una protección especial impuesta por la legislación sectorial, sino también cuando, al margen de ello, el planeamiento general lo decidiera para preservar los valores arqueológicos $\left(\right.$ art. 9.2 $2^{\mathrm{a}}$ ). Ahora la misma idea late en el art. 21.2.a) del Texto Refundido de la Ley de Suelo de 2015. Y naturalmente se refleja en la legislación urbanística autonómica. Por ejemplo, el art. 46.1 de la Ley de Ordenación Urbanística de Andalucía dispone que son suelo no urbanizable los terrenos que el PGOU adscriba a esta clase de suelo por estar sujetos a algún régimen de protección por la legislación de preservación del patrimonio histórico o cultural o, al margen de la legislación sectorial, por "ser merecedores de algún régimen especial de protección o garante del mantenimiento de sus características, otorgado por el propio PGOU, por razón de los valores e intereses en ellos concurrentes de carácter ... histórico". En la legislación de patrimonio histórico es ilustrativo el art. 54 de la Ley de Patrimonio Cultural de Castilla y León que dispone que los lugares en que se encuentren bienes arqueológicos sean clasificados como suelo rústico de protección cultural, salvo que se localicen en zonas urbanas o clasificadas como urbanizables con anterioridad a la entrada en vigor de esta Ley.

${ }^{34}$ S. MARTÍN VALDIVIA, "La protección del patrimonio arqueológico andaluz y la figura del obligado «mecenazgo» arqueológico: ¿solución o problema?", Patrimonio Cultural y Derecho, $\mathrm{n}^{\circ} 3$ (1999), pp. 163 y ss. 
puede decirse, en consecuencia, que no habrá derecho a indemnización porque el daño que sufren los promotores no es antijurídico ya que tienen el deber legal de soportarlo sin límite, incluso aunque los gastos, daños y perjuicios sean muy elevados. A cambio de ello, algunas de esas leyes, quizá atisbando las consecuencias ruinosas que este régimen puede tener en algunos supuestos, prevén la concesión de ayudas públicas pero muy diversas en cuanto a su concreción, obligatoriedad y cuantía. Todo esto está además presidido por una muy amplia discrecionalidad ya no sólo a la hora de imponer o no las actuaciones arqueológicas sino también en cuanto a su amplitud, alcance y duración; discrecionalidad al imponer la intervenciones y, después, al autorizar las impuestas y condicionar su ejecución; y discrecionalidad, de nuevo, en la concesión de ayudas y su importe.

La situación descrita no merece un juicio favorable casi desde ningún punto de vista. Quizá ni siquiera haya dado lugar a un adecuado desarrollo de las investigaciones arqueológicas sino que más bien haya originado disfunciones ${ }^{35}$. Pero, al margen de ello, desde el punto de vista jurídico, presenta deficiencias y suscita dudas. Por lo pronto, genera desigualdades patentes, no ya de una Comunidad Autónoma a otra, sino de un municipio a otro y hasta de una parcela a otra sin que normalmente se puedan paliar por los mecanismos de equidistribución de las cargas urbanísticas. Por otra parte, otorga una discrecionalidad administrativa demasiado amplia, fuente, si no de arbitrariedad y abusos, sí de inseguridad sobre lo que habrá que hacer, durante cuánto tiempo y con qué coste y, otra vez, de desigualdades. Y no hace falta decir que esta discrecionalidad que permite imponer deberes económicos a los particulares sin ningún coste para la Administración presenta riesgos que, además, se agudizan si los órganos que la ejercen están dominados por los propios arqueólogos. Por lo demás, la ejecución administrativa de este régimen no suele ser un modelo de transparencia ni de cumplimiento escrupuloso de principios que siempre han debido regirla y que ahora consagra formalmente el art. 39.bis 1 de la Ley 30/1992: "Las Administraciones Públicas que en el ejercicio de sus respectivas competencias esta-

${ }^{35}$ A este respecto I. RODRÍGUEZ TEMIÑO, Arqueología urbana..., cit., pp. 61, 66, 68-70, 73, 120,153 , afirma que estas regulaciones han supuesto un aumento espectacular de las intervenciones preventivas que, muy por encima de la capacidad de los equipos para estudiarlas, ha superado "las posibilidades de digestión científica posterior", de modo que ni se conocen bien los resultados ni se estudian seriamente ni se ven sus frutos científicos ni sociales; todo ello, además, con la irracionalidad de excavaciones solar a solar, sin una visión global, sin continuidad, sin "criterios de rentabilidad científica". Además, se hace arqueología "en función de la posibilidad real de financiarla y no del interés de los restos existentes o presuntos". Parece, dice, que "resulta suficiente contrapartida el hecho de que la arqueología urbana se haya convertido en el banderín de enganche para universitarios recién licenciados de manera que ni siquiera se saca partido a esas numerosas excavaciones". "Lo peor es que la ruptura del ciclo de investigación de la arqueología impide su reversión social, fin último de la misma y justificación de su propia existencia y de las obligaciones impuestas a cuantos participan en la actividad constructiva...". 
blezcan medidas que limiten el ejercicio de derechos individuales o colectivos o exijan el cumplimiento de requisitos para el desarrollo de una actividad, deberán elegir la medida menos restrictiva, motivar su necesidad para la protección del interés público, así como justificar su adecuación para lograr los fines que se persiguen, sin que en ningún caso se produzcan diferencias de trato discriminatorias". Lo mismo proclama ahora elart. 4.1 de laLey 40/2015, de Régimen Jurídico del Sector Público.

Sobre todo es dudoso que estos regímenes autonómicos respeten siempre el contenido esencial de la propiedad y puedan reconocerse como expresión de su función social. Aceptemos la competencia de las Comunidades Autónomas para aprobarlos e incluso admitamos que no vulneran, porque no tienen que respetarla, la actual LPHE. Aceptemos también que no supone arbitrariedad de los poderes públicos el que establezcan para bienes menos interesantes (las zonas con simple presunción de restos arqueológicos de cualquier valor) reglas más tuitivas que las que la Ley estatal previó para los de máximo valor. Admitamos asimismo que respetan, aunque no siempre lo hayan hecho, la reserva de ley. Y finalmente admitamos, por supuesto, que "la propiedad obliga". Pero, incluso así, ni la ley puede imponer a todo ni cualquier deber o carga queda amparado por la función social de la propiedad. Y cabría sostener que los deberes que imponen al promotor las leyes autonómicas desbordan la función social de la propiedad en tanto que son prestaciones personales y patrimoniales para contribuir positivamente al desarrollo de las investigaciones arqueológicas sobre unos restos que, para colmo, son de dominio público ${ }^{36}$. Y, sin llegar tan lejos, al menos pa-

${ }^{36}$ En esta línea, radical y sugerente es el planteamiento de LEÑERO BOHORQUEZ en la tesis ya citada: partiendo de que los bienes arqueológicos protegidos no son titularidad del sujeto obligado, sino de dominio público, y de que lo que aquí se impone no es sólo soportar o no hacer, sino un hacer, concluye que la función social de la propiedad, aunque sí permite fundamentar un restringido aprovechamiento urbanístico de los terrenos privados, "no alcanza a justificar la imposición a los propietarios de los costes de las actividades arqueológicas preventivas o de urgencia". Quizás en la misma línea, pero más moderadamente, pudiera decirse que el problema no está tanto en que se imponga un hacer sino que en ese hacer tiene como finalidad algo más que evitar que las obras proyectadas dañen los restos arqueológicos. Así, en la medida en que los estudios previos sólo persigan identificar los restos para, con ese dato, determinar lo que puede o no puede construirse y cómo hacerlo sin dañarlos, podrían ser justificados como una carga para hacer efectiva la función social de la propiedad. Es lo mismo que permite imponer, como observa la propia LEÑERO, el principio "quien contamina paga". Pero desbordaría esa función social de la propiedad y tampoco quedaría cubierta por el principio "quien contamina paga", la imposición de intervenciones arqueológicas que van más allá y tienen como finalidad realizar una completa investigación científica y acrecentar los conocimientos sobre los restos. Esto, si acaso, sólo podría justificarse por la vía que ya apuntamos antes (supra II.1): como podría denegarse la autorización para realizar la obra porque dañaría restos arqueológicos y así quedarían estos incólumes para que alguna vez sean estudiados con fondos públicos, se da la alternativa de autorizar las obras a condición de que antes se hagan y se costeen todas las investigaciones arqueológicas que permitan contar de antemano con la información científica que los restos suministran y que es lo que realmente se quiere preservar. 
rece que hay que reconocer que no se respetará el contenido esencial de la propiedad y se desbordará lo que cabe dentro de su función social cuando, como no es improbable, se impongan cargas desproporcionadas que, incluso, eventualmente, hagan perder utilidad económica a la propiedad y a la inversión prevista para las obras $^{37}$.

El juicio desfavorable no cambia por el hecho de que, en general, los promotores hayan aceptado sin rechistar todas estas cargas, incluso las que imponían simples reglamentos o planes urbanísticos ${ }^{38}$. Tampoco cambia al comprobar que algunos tribunales, como vimos que ha hecho el TSJ de Galicia, hayan realizado interpretaciones acrobáticas que han moderado, por no decir desdibujado, el régimen de las leyes autonómicas, lo que más bien, además de demostrar la insatisfacción que produce la regulación actual, es origen de más inseguridad y de nuevas desigualdades.

Sí se paliaría algo la situación si se aceptara, como ha propuesto Baño León con carácter general ${ }^{39}$ y como creo correcto y posible aplicar aquí, que los jueces ordinarios, sin cuestionar la constitucionalidad de la ley que contemple abstractamente estas cargas o que confiera potestades a la Administración para imponerlas caso por

${ }^{37}$ Desde este punto de vista, algunos casos se pueden asemejar al del deber de saneamiento de suelos contaminados al que el Tribunal Constitucional alemán ha puesto frenos para evitar que pueda privar a la propiedad de toda utilidad económica, como ha explicado entre nosotros J. M. BAÑO LEÓN en "Los suelos contaminados: obligación de saneamiento y derecho de propiedad", Revista Aranzadi de Derecho Ambiental, n” 2, y en "El contenido esencial de la propiedad en el contexto del Derecho europeo", Derechos fundamentales y otros estudios en homenaje al prof. Dr. Lorenzo Martín-Retortillo, Zaragoza, 2008, vol. 2, pp. 1787 y 1792-1793. De hecho, el mismo BAÑO, en el trabajo últimamente citado, p. 1795, apunta la aplicación de estas ideas a ciertos deberes de conservación del patrimonio histórico. Pero en nuestro caso, además, no se trata sólo de evitar daños sino normalmente de contribuir positivamente a la investigación arqueológica. Por su parte, J. BERMÚDEZ SÁNCHEZ, El derecho de propiedad..., cit., pp. 128 y ss., considera que la imposición de estas intervenciones arqueológicas son límites que pueden resultar desproporcionados e irrazonables y, por tanto, desbordar la función social de la propiedad.

${ }^{38}$ Lo han hecho, de una parte, porque podían repercutir estos costes arqueológicos en el precio de venta de sus construcciones. Pero, además de que la situación ha cambiado radicalmente y ya no es fácil repercutir esos costes sobre el precio final de las viviendas, máxime si son de protección oficial, esto es una prueba de que el sistema engendrado perjudica no propiamente a los promotores, sino al conjunto de los ciudadanos en su derecho al acceso a una vivienda. Lo han hecho también por considerar que, ante tal maraña legislativa y administrativa, era mejor asumir esas intervenciones que enfrentarse con la Administración, en especial con sus arqueólogos, y sufrir más retrasos. Y esto lo que demuestra es que la amplia discrecionalidad reinante en este ámbito, unida a una regulación embrollada, es un serio obstáculo para un control judicial efectivo.

${ }^{39}$ J. M. BAÑO LEÓN en "El contenido esencial del derecho de propiedad...”, cit., pp. 1792 y ss. 
caso, sí puedan enjuiciar la constitucionalidad de los concretos actos administrativos que la aplican en un supuesto determinado; en concreto, enjuiciar si los efectos de cada acto administrativo de aplicación, aunque permanezcan formalmente dentro del marco de la ley habilitante, mantienen o suprimen la utilidad económica de la propiedad: si comprueban que no es así, podrían, o bien anular el acto en tanto que impuso cargas antieconómicas, o bien conceder una indemnización en tanto que el propietario no tendría el deber jurídico de soportar la lesión patrimonial que entrañan.

Aun admitiéndolo así, se trataría de una solución parcial y de difícil articulación en la práctica. La situación descrita merece una corrección más profunda y general. Y puede y debe hacerse modificando la LPHE que es el origen de los males aludidos. De una parte, porque no expuso el fundamento constitucional de la competencia estatal que la sustentaba. De otra parte, porque estableció una protección insuficiente del patrimonio arqueológico frente al riesgo que entrañan las obras. Lo primero, junto con la STC 17/1991, de 31 de enero, dejó expedito un ancho camino a las legislaciones autonómicas más dispares. Lo segundo hizo que las leyes autonómicas ni siquiera encontraran en la LPHE un referente válido y recorrieran ese camino estableciendo sistemas de protección arqueológica completamente distintos. Pero ambos defectos pueden y deben corregirse. Para lo que aquí nos ha ocupado la nueva legislación estatal encontraría su fundamento en el art. 149.1.1 ${ }^{\text {a }}$ CE que permite al Estado aprobar una regulación mínima que garantice las condiciones básicas de igualdad en el ejercicio de los derechos y en el cumplimiento de los deberes aquí implicados. Por lo menos es seguro que, en conjunción con el art. 149.1.28 a y 2 CE, justifica esa regulación muchos más que en otros sectores en los que el TC lo ha admitido ${ }^{40}$. Va más allá de mi propósito y de mi capacidad perfilar ese régimen basado en el art. 149.1.1 ${ }^{\text {a }}$ CE pero oso aquí sugerir que debería dejar un amplio campo a las leyes autonómicas para que fueran ellas las que decidieran en qué medida y forma pretenden extender los principios de prevención y hasta de precaución en la protección del patrimonio arqueológico frente a obras. Pero, precisamente para garantizar la igualdad básica, debería imponer unas condiciones mínimas en cuanto a la declaración y delimitación de las zonas en que quepa imponer intervenciones arqueológicas pre-

${ }^{40}$ J. ALONSO GARCÍA, "Las cargas arqueológicas...", cit., p. 190, que también "echa en falta una ordenación cohesionada" que garantice una cierta igualdad" y que afirma que "podría el Estado garantizar unas condiciones mínimas que permitan clarificar en qué medida deben asumir los particulares las obligaciones arqueológicas y cuáles son los conceptos indemnizables y los mecanismos para hacer efectiva la compensación", entiende que la "legitimación constitucional para abordar tal tarea... la proporciona el artículo 149.1.18 a de la Constitución Española que atribuye al Estado la competencia exclusiva en materia de expropiación forzosa y sobre el régimen básico de la responsabilidad de las Administraciones públicas". Me parece, sin embargo, que este fundamento constitucional es más discutible. 
ventivas tras seguir un procedimiento que asegurase la participación de los propietarios de los terrenos afectados. Y, sobre todo, debería establecer ciertos máximos en cuanto a la naturaleza de las intervenciones obligadas, a su coste y a su duración, máximos a partir de los cuales, por la vía de ayudas o de indemnizaciones, la financiación sería pública. Así no sólo se evitarían cargas antieconómicas para los particulares sino que indirectamente, al poder generar gastos públicos a partir de cierto punto, introduciría una garantía de mesura y proporcionalidad en las decisiones administrativas sobre las intervenciones pertinentes. 